\title{
Technique policy for concurrent development of natural and artificial water flooding of strong edge water reservoir: A case study of central layer Yu-III of Akshabulak oilfield
}

\author{
Zhang Angang, Fan Zifei, Zhao Lun, Wang Jincai, Zhang Xiangzhong, Song Heng, and Hou Qingying \\ PetroChina Research Institute of Petroleum Exploration \& Development, Beijing, China
}

\begin{abstract}
The central layer Yu-III in Akshabulak oilfield is a sandstone reservoir with strong edge water, whose major development characteristics are high oil recovery rate and heterogeneous water invasion. Aiming at this problem, the development policy chart of concurrent displacement of natural water and injected water is established on the basis of material balance principle. Injection-production ratio and oil recovery rate are the main controlling factors for the concurrent displacement of natural water and injected water. Each injection-production ratio corresponds with only one rational oil recovery rate, and the rational oil recovery rate increases with the injection-production ratio. When the actual injection-production ratio of the central Yu-III reservoir is 0.9 , the rational oil recovery rate should be $4 \%$.
\end{abstract}

\section{Introduction}

During the development of strong edge water reservoir, how to maximize the usage of the driving energy of natural water and minimize the investment of artificial water injection becomes the urgent issue at present [1-2]. Therefore, for concurrent development of natural and artificial water flooding, it is significant to confirm the main influence factor and establish the correct technique policy [3-5]. By taking example of central layer Yu-III of Akshabulak oilfield, the development technique policy charts for concurrent development of natural and artificial water flooding of strong edge water reservoir are printed.

\section{Geologic and production characteristics of central layer Yu-III}

Akshabulak oilfield is located in Aryskum depression of South Turgai Basin, which is a NE structure controlled by faults. The oilfield is divided into three parts: the center, east and south part. Moreover, the center part is separated from the south part by EW fault. And the south part has more fault than the other two parts. As a whole, Akshabulak oilfield is a multi-layered anticline sandstone reservoir. The reservoir depth ranges from $1550 \mathrm{~m}$ to $1950 \mathrm{~m}$. There are 7 oil layers vertically, which includes M-II-1, M-II-2, Yu-0-1, Yu-0-2, Yu-I, Yu-II and Yu-III (Fig. 1). The main rock types of central layer Yu-III are grit stone and medium sandstone. The average porosity is $25.8 \%$, and the average permeability is $1320 \mathrm{mD}$. Generally, the reservoir is a high porosity and super high permeability reservoir, but has strong heterogeneity. The central layer Yu-III was firstly put into production in October, 1996, and was transformed into out edge water flooding in November, 2002. The reservoir is developed by high oil recovery. The oil recovery rate was maintained at $3 \%$ since 2004 , and the peak was high to $4.4 \%$.

\section{Technique policy for concurrent development of natural and artificial water flooding of strong edge water reservoir}

\subsection{Model establishment of reservoir engineering evaluation model}

In order to carry out the concurrent development of natural and artificial water flooding efficiently, such influencing factors as water body energy, reserves, oil recovery rate and injection-production ratio are considered comprehensively (Fig. 2). Hence, how to define the production contribution ratio of natural water drive and artificial water flooding, becomes the urgent development issue at present. 


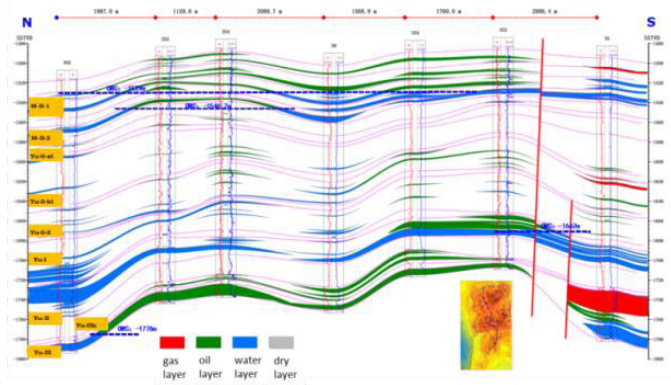

Fig .1 The north-south reservoir profile of Akshabulak oilfield

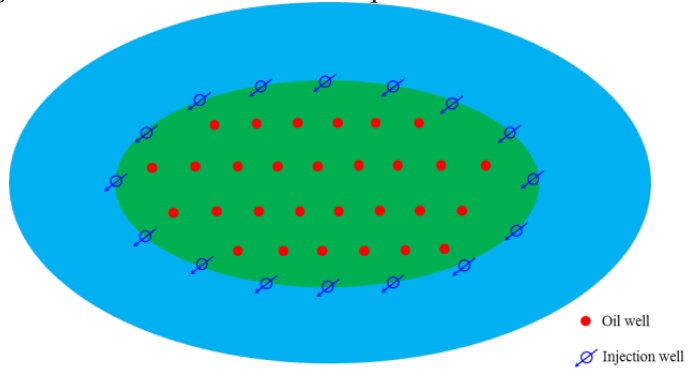

Fig. 2 Sketch map of out edge water flooding for strong edge water reservoir

According to material balance principle, the cumulative oil production in reservoir condition equals the fluid swelling capacity plus cumulative water injection [6-9].

$$
\begin{aligned}
N_{p}\left[B_{o}+\left(R_{p}-R_{s}\right) B_{g}\right]= & N B_{o i}\left[\frac{B_{o}-B_{o i}+\left(R_{s i}-R_{s}\right) B_{g}}{B_{o i}}+\frac{C_{w} S_{w c}+C_{f}}{1-S_{w c}} \Delta p\right](1) \\
& +\left(W_{e}+W_{i}-W_{p}\right) B_{w}
\end{aligned}
$$

Here, $N_{\mathrm{p}}$ is cumulative oil production at standard condition, $\mathrm{m}^{3} ; B_{\mathrm{o}}$ is oil volume factor at current condition, $\mathrm{m}^{3} / \mathrm{m}^{3} ; B_{\mathrm{g}}$ is gas volume factor at current condition, $\mathrm{m}^{3} / \mathrm{m}^{3} ; B_{\mathrm{oi}}$ is oil volume factor at initial condition, $\mathrm{m}^{3} / \mathrm{m}^{3}$; $R_{p}$ is production gas oil ratio, $\mathrm{m}^{3} / \mathrm{m}^{3} ; R_{\mathrm{s}}$ is dissolved gas oil ratio at current condition, $\mathrm{m}^{3} / \mathrm{m}^{3} ; R_{\mathrm{si}}$ is dissolved gas oil ratio at initial condition, $\mathrm{m}^{3} / \mathrm{m}^{3} ; C_{f}$ is pore compressibility coefficient, $\mathrm{MPa}^{-1} ; C_{\mathrm{w}}$ is water compressibility coefficient, $\mathrm{MPa}^{-1} ; B_{\mathrm{w}}$ is water volume factor at current condition, $\mathrm{m}^{3} / \mathrm{m}^{3} ; S_{\mathrm{wc}}$ is irreducible water saturation, fraction; $\Delta p$ is reservoir pressure difference, $\mathrm{MPa} ; W_{\mathrm{e}}$ is cumulative water influx, $\mathrm{m}^{3} ; W_{\mathrm{i}}$ is cumulative water injection, $\mathrm{m}^{3} ; W_{\mathrm{p}}$ is cumulative water production, $\mathrm{m}^{3}$.

In equation (1), cumulative water influx is obtained by Fetkovitch method [10-11]. The water influx equation about Fetkovitch method is shown as follows:

Hereinto

$$
W_{e}=\frac{W_{e i}}{p_{i}}\left(p_{i}-p\right)\left(1-e^{-\frac{J p_{i}}{W_{e i}}}\right)
$$

$$
W_{e i}=V_{w}\left(C_{w}+C_{f}\right) p_{i} \quad J=\frac{2 \pi \varphi k h a}{\mu_{w}\left(\ln \frac{r_{e}}{r_{o}}-\frac{3}{4}\right)}
$$

Here, $W_{e i}$ is the maximum water flux potential, $\mathrm{m}^{3} ; V_{w}$ is the volume of water body, $\mathrm{m}^{3} ; p_{i}$ is initial reservoir pressure of water body, $\mathrm{MPa} ; J$ is water influx coefficient, $\mathrm{m}^{3} /(\mathrm{d} \cdot \mathrm{MPa}) ; \varphi$ is reservoir circumference coefficient, $\varphi=\theta / 360 ; \theta$ is water influx angle, degree; $k$ is formation permeability, $\mu \mathrm{m}^{2} ; h$ is water formation thickness, $\mathrm{m}$; $a$ is conversion coefficient, $a=86.4 ; \mu_{w}$ is formation water viscosity, $\mathrm{mPa} \cdot \mathrm{s} ; r_{e}$ and $r_{o}$ are water body radius and reservoir radius, $\mathrm{m} ; t$ is development time, $\mathrm{d} ; p$ is the reservoir pressure at current condition, $\mathrm{MPa}$.

During the reservoir development, the actual reservoir pressure changes with the development time. Thus, the water influx at the time of $\Delta t_{n}$ can be expressed as:

$$
\Delta W_{e n}=\frac{W_{e i}}{p_{i}}\left(\bar{p}_{n-1}-p_{n}\right)\left(1-e^{-\frac{J p_{i}}{W_{e i}} \Delta t_{n}}\right)
$$

Then, the average pressure of water body $\bar{p}_{w n-1}$ can be expressed as:

$$
\bar{p}_{n-1}=p_{i}\left(1-\frac{\sum_{j=1}^{n} \Delta W_{e j}}{W_{e i}}\right)
$$

The cumulative water influx is the sum of water influx at several time slots.

$$
W_{e}=\sum_{j=1}^{n} \Delta W_{e j}
$$

From the above equation, the reservoir water influx is related to reservoir pressure closely. Hence, in order to predict the water influx at different oil recovery rate and injection-production ratio, the average reservoir pressure should be confirmed firstly. If the initial reservoir pressure, production history data and P.V.T parameters are given, the reservoir pressure at different time can be calculated by trial-and-error method. The detailed calculated process is shown as follows:

(1) Assuming the reservoir pressure is $p^{\prime}$, each part of material balance equation (1) is calculated. Hereinto, cumulative water influx $W_{e}$ is obtained by the equation (3)-(5); Cumulative water production $W_{p}$ is obtained by water-drive characteristic curve $\lg W_{p}=a N_{p}+b$;

(2) Judge the equality of material balance equation (1). If the equality is met, the current reservoir pressure is $p^{\prime}$. If the equality is not met, a new pressure $p$ " is assumed and the above calculated process is repeated until the equality is met.

The cutoff condition of the trial-and-error method is that the reservoir pressure is less than the abandon pressure, or the development time reaches the end of contract term.

The production contribution ratio of natural water drive and artificial water flooding can be expressed as:

$$
\begin{gathered}
D_{w e}=\frac{W_{e} B_{w}}{N_{p}\left[B_{o}+\left(R_{p}-R_{s}\right) B_{g}\right]+W_{p} B_{w}} \\
D_{w i}=\frac{W_{i} B_{w}}{N_{p}\left[B_{o}+\left(R_{p}-R_{s}\right) B_{g}\right]+W_{p} B_{w}}
\end{gathered}
$$

Here, $D_{w e}$ and $D_{w i}$ are the drive index of natural water drive and artificial water flooding, dimensionless.

By evaluating the production contribution ratio of natural water drive and artificial water flooding at different time, the synergistic effect of reservoir energy can be reflected to provide some evidences for the future reservoir development adjustment

\subsection{Development technique policy charts}

On the basis of the geologic and operational parameters, 
the relevant reservoir engineering model is established. Such development indexes as reservoir pressure level, production contribution ratio of natural water drive and artificial water flooding, and oil recovery percent are studied by the above reservoir engineering model.

(1) Reservoir pressure level

Reservoir pressure variation law under different injection-production ratio and oil recovery rate is researched. Meantime, the charts of reservoir pressure level and cumulative water influx are printed (Fig. 3).

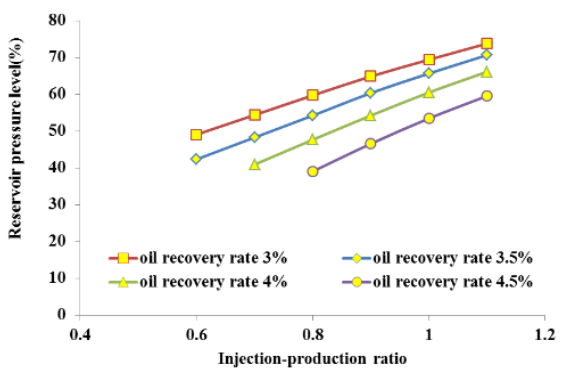

(a)Reservoir pressure level

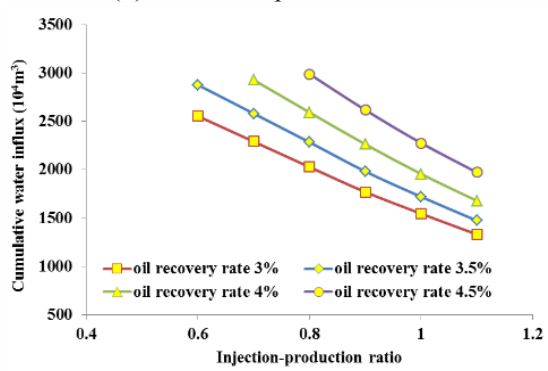

(b)Cumulative water influx

Fig. 3 Charts of reservoir pressure level and cumulative water influx under different injection-production ratio and oil recovery rate

Fig. 3 shows that when oil recovery rate is constant and the injection-production ratio increases, the cumulative water influx decreases and the reservoir pressure level increases. When the injection-production ratio is constant and oil recovery rate increases, the cumulative water influx increases and the reservoir pressure level decreases. In order to maintain the reservoir energy, injection-production ratio should be increased and oil recovery rate should be decreased.

(2) Production contribution ratio of natural water drive and artificial water flooding

Based on the reservoir engineering model, the charts of production contribution ratio of natural water drive and artificial water flooding are printed (Fig. 4).

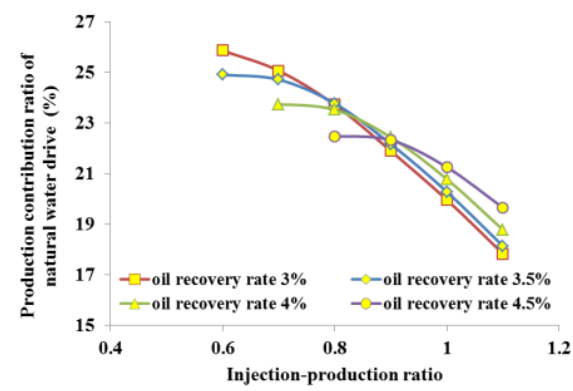

(a)Production contribution ratio of natural water drive

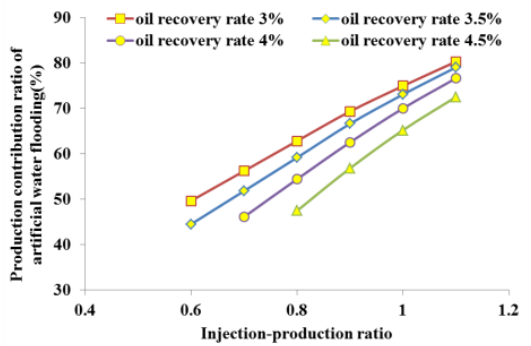

(b)Production contribution ratio of artificial water flooding

Fig. 4 Production contribution ratio of natural water drive and artificial water flooding under different injection-production ratio and oil recovery rate

Fig. 4 shows that when injection-production ratio is relatively small and oil recovery rate increases, the production contribution of natural water drive decreases; when injection-production ratio is relatively large and oil recovery rate increases, the production contribution of natural water drive increases. Whether oil recovery rate is small or large, the production contribution of natural water drive decreases with increasing injection-production ratio. On the other hand, the production contribution of artificial water flooding increases with injection-production ratio, and decreases with increasing oil recovery rate.

(3) Oil recovery percent

Considering the contract term of Akshabulak oilfield, the chart of oil recovery percent under different injection-production ratio and oil recovery rate is also printed (Fig. 5).

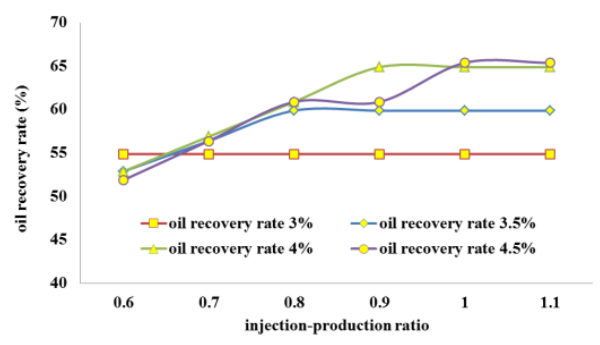

Fig. 5 Oil recovery percent under different oil recovery rate and injection-production ratio

Fig. 5 shows that oil recovery rate increases with injection-production ratio at the same oil recovery rate. However, when the oil recovery rate reaches to a certain level, the increase rate of oil recovery percent becomes slow. Each oil recovery rate refers to a rational injection-production ratio, and rational oil recovery rate increases with injection-production ratio (Fig. 6a).

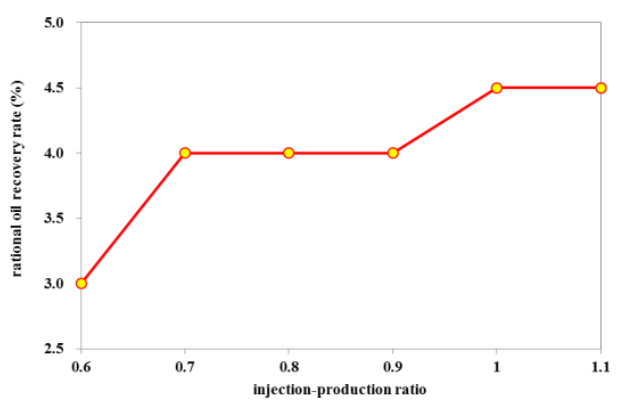

(a) Only consider oil recovery percent 


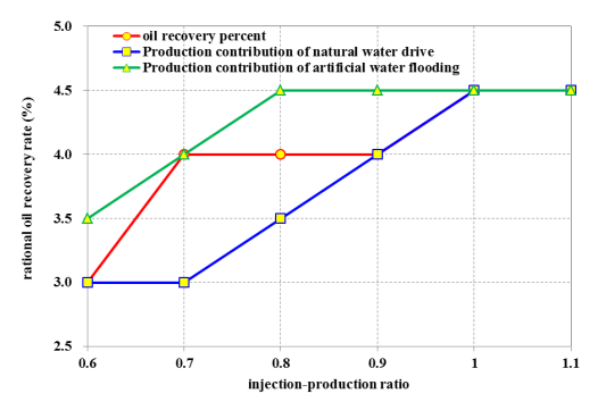

(b)consider oil recovery percent and production contribution ratio of natural water drive and artificial water flooding

Fig. 6 Relationship between rational oil recovery rate and injection-production ratio

For the water flooding of the oil reservoir with strong edge water energy, how to maximize the displacement of natural water and minimize the investment of artificial water injection becomes the urgent development issue at present. Thus, aimed at the development indexes of oil recovery percent, production contribution ratio of natural water drive and artificial water flooding, the relationship chart between oil recovery rate and injection-production ratio is established (Fig. 6b). For Fig. 6b, it can be seen that the best combinations of injection-production ratio and oil recovery rate are $(1,4.5 \%)$ and $(1.1,4.5 \%)$.

\subsection{Validity verification of the technique policy charts}

On the basis of the above reservoir engineering model, the change of drive index at different time is calculated. Since the reservoir is developed by water flooding in 2002, the drive index of natural water, dissolved gas and elastic energy decreased with increasing injection-production ratio, but the drive index of artificial water flooding increased with injection-production ratio (Fig. 7). In 2016, the cumulative water influx of central layer Yu-III is $1211 \times 10^{4} \mathrm{~m}^{3}$. Meantime, the drive index of natural water is 0.21 , and the drive index of artificial water flooding is 0.72 .

Assuming the reservoir injection-production ratio is constantly 0.9 , the development effect at different oil recovery rate of $1 \%, 2 \%, 2.5 \%, 3 \%, 4 \%$ and $5 \%$ is studied by reservoir numerical simulation. The research results shows that different oil recovery cases have different oil recovery percent during the contract term. Furthermore, the oil recovery percent of the case of oil recovery rate $4 \%$ is $5.8 \%$ more than the case of oil recovery rate $1 \%$ (Fig. 8). For Fig. 6b, in order to maximize oil recovery percent and production contribution ratio of natural water drive, the best combination of injection-production ratio and oil recovery rate is also $(0.9,4 \%)$. Therefore, the numerical simulation results verify the effectiveness of the above reservoir engineering model.

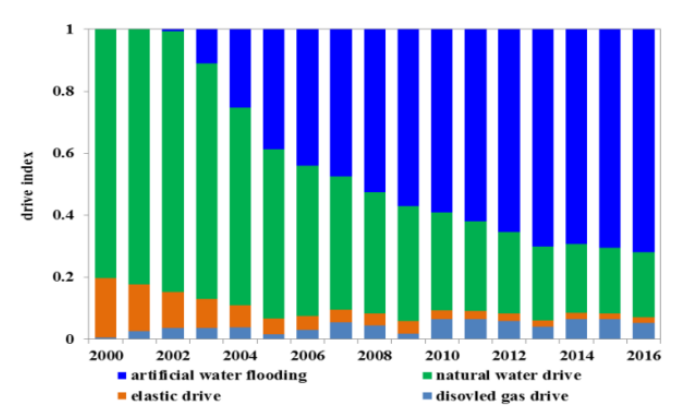

Fig. 7 Variation of drive index and injection-production ratio for central layer Yu-III

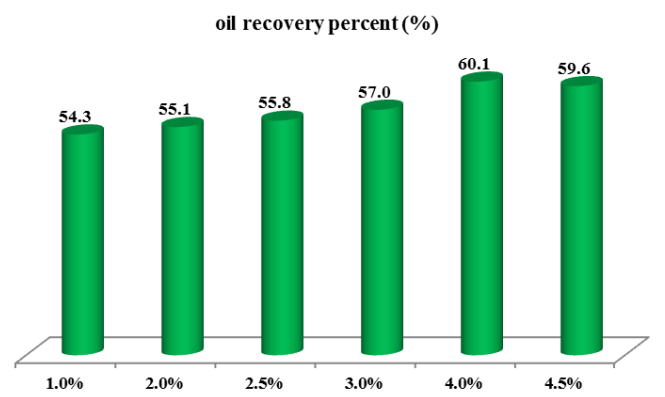

Fig. 8 Ultimate recovery factor and recovery percent of contract term under different oil recovery rate

\section{Conclusion}

Technique policy charts for concurrent development of natural and artificial water flooding of strong edge water reservoir are established, which indicates that injection-production ratio and oil recovery rate are the main influencing factors for the concurrent development. Each oil recovery rate refers to a rational injection-production ratio, and rational oil recovery rate increases with injection-production ratio. When the injection-production ratio of central layer Yu-III is 0.9, the rational oil recovery rates obtained by technique policy charts and reservoir numerical simulation are both $4 \%$, which shows that the above technique policy charts is available.

\section{References}

1. Zhang Rui, Yu Qitai. An analysis of the development efficiency of a naturally water drive sandstone oil reservoir[J]. Petroleum Exploration and Development, 18(3): 46-54 (1991)

2. $\mathrm{Mu}$ Longxin, $\mathrm{Wu}$ Xianghong, Huang Qizhi. Development theory and technology of high pour point oil reservoir[M]. Beijing: Petroleum Industry Press, 108-115 (2015)

3. Jin Yong, Tang Jiandong, Zhao Juan, et al. Determining method for reasonable drawdown pressure of oil reservoir with edge and bottom water[J]. Acta Petrolei Sinica, 24(1): 68-72 (2003)

4. Hou Jian, Zhang Yanhui, Gong Ruxiang. Efficient development technique of high permeability sweet oil active edge water drive reservoir: case of Pai2 reservoir of Chunguang Oilfield[J].Petroleum Geology and Recovery Efficiency, 19(6): 82-86 
(2012)

5. K. Ayeni, R. Wattenbarger, J. Maggard. Estimating water production behavior from edge water drive in a monocline reservoir[C]. SPE 114593-MS (2008).

6. Tang Ligen, Wang Jieming, Bai Fengjuan, et al. Inventory forecast in underground gas storage based on modified material balance equation[J]. Petroleum Exploration and Development, 41(4): 480-484 (2014)

7. Jiang Hanqiao, Yao Jun, Jiang Ruizhong. Principle and method of reservoir engineering[M]. Dongying: China University of Petroleum Press, 200-208 (2006)

8. Gao Chentai, Lu Tao, Gao Weixin, et al. Muti region material balance method and its use in the performance prediction and optimal well pattern design of edge water reservoir[J]. Petroleum Exploration and Development, 33(1):103-106 (2006)

9. Fan Zifei, Cheng Linsong, Song Heng, et al. Fluid interface moving for the concurrent production of gas cap and oil ring of gas cap reservoirs[J]. Petroleum Exploration and Development, 42(5):624-631 (2015)

10. M.J. Fetkovich. A simplified approach to water influx calculations-finite aquifer systems[J]. Journal of Petroleum Technology, 23(7): 814-828 (1971)

11. Lu Kefeng. Applicability analysis on classical empirical relation $\ln \omega=\mathrm{B} \operatorname{lnR}$ of water invasion prediction for water drive gas reservoirs[J].China Offshore Oil and Gas, 28(06): 40-45 (2016) 